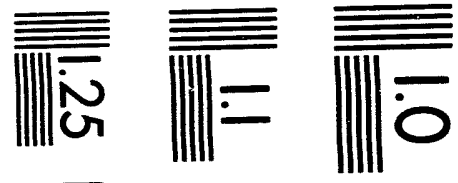

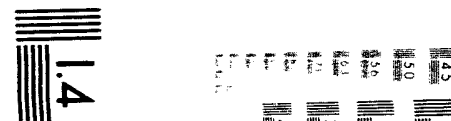

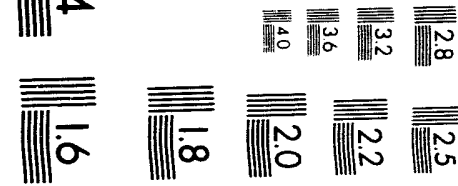



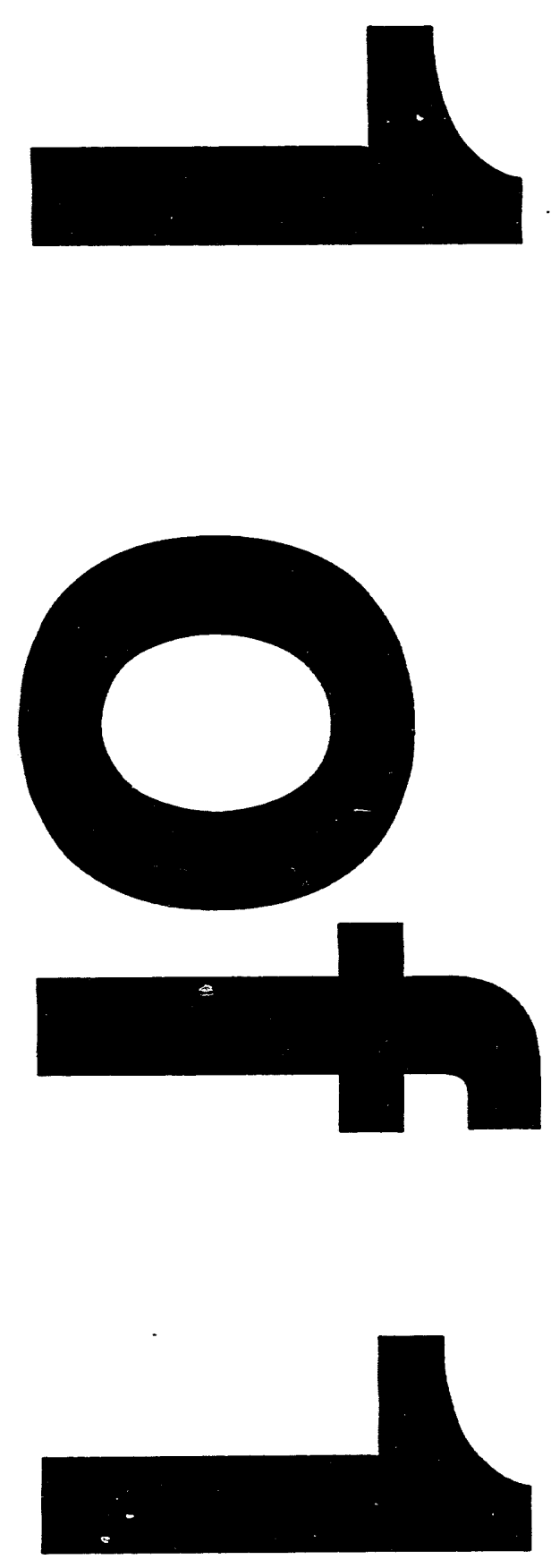


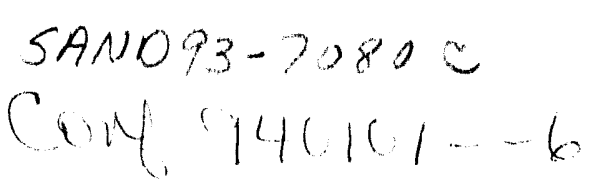

\title{
AN F2D ANALYSIS OF THE FLOW INSTABILITY TEST (FIT) EXPERIMENT
}

\author{
Ahti Suo-Anttila \\ Science Applications International Corporation \\ 2109 Air Park Rd. S.E. \\ Albuquerque N.M.
}

(505) 247-8787

\begin{abstract}
The F2D code was used to analyze the Flow-Instability-Test (FIT) experiments at Brookhaven National Laboratories. A one-dimensional analysis of the experiment indicated that at the higher temperature levels the element should be unstable. The experimental data corroborated this theory. The two-dimensional simulation behaved in a manner that was very similar to the experimentally measured behavior. In conclusion, the FIT experimental analysis yields partial code validation of F2D, and it also validates the methodology that is used in analyzing thermal flow stability.
\end{abstract}

OCi 221993 OSTI

\section{INTRODUCTION}

The Flow-Instability-Test (FIT) experiment was conducted at Brookhaven National Laboratories (BNL) in 1993. The experiment was intended to be used as an experimental validation or refutation of the existence of thermally driven flow instabilities (Suo-Anttila 1993) or maldistributions that had been predicted to occur under certain conditions of flow and power in actual particle bed nuclear fuel elements.

This paper reports the analysis of the FIT experiments using the F2D code and the same methodology that was used in analyzing the stability of the actual nuclear fuel elements. The F2D code is a general use two-dimensional compressible gas flow code that will model flow in heated porous media. To this end a successful analysis will provide partial validation of the F2D code as well as the analytical approach to the stability issue.

A schematic diagram of the FIT experiment is depicted in Figure 1. The experiment apparatus consisted of two sintered porous metal cylinders that acted as hot and cold frits. The nuclear fuel was simulated by an electrically heated screen that was coiled between the hot and cold frits. The screen was insulated by a thin coating of plasma sprayed alumina which prevented electrical shorting. During the test the screen was heated electrically and cold helium was forced through the element, while temperatures were measured at various locations on the hot frit.

The results of the experiments can be summarized in two tests. The first test is called Low PHI, which represents a low value of the outlet to inlet temperature ratio, and the second test is called High PHI which represents a large value of the temperature ratio. 
Figure 1. A Schematic Diagram of the FIT Element

The Low PHI test was run with room temperature inlet gas. It displayed a spread in thermocouple temperatures, but no sign of instability. The second test, called High PHI, was conducted with a helium inlet temperature of approximately $100 \mathrm{~K}$, and run with a nearly constant flow rate, but the power was set at different levels for approximately 1 minute at each level. During the test the thermocouple data indicated a very large spread in the temperature as the power level was increased. Instability was inferred from the fact that some temperatures decreased even though the electric power was increased.

\section{STABILITY ANALYSIS}

The existence of thermally driven flow instabilities has been the subject of several papers recently (Suo-Anttila 1993, Black 1993, Witter et. al. 1993). There have been many different approaches to the issue of stability varying from perturbation methods to direct numerical simulations. The F2D code is being used in this analysis, therefore a numerical approach is used. The numerical approach to the issue of stability, as presented here, consists of two steps. The first step, is a one-dimensional analysis that can be used to infer the existence of instabilities. The second step, is to model the experimental apparatus in two-dimensions to see if the predicted response is similar to the measured response.

\section{ONE-DIMENSIONAL ANALYSIS}

The one-dimensional numerical approach to the issue of stability was outlined in a previous paper (Suo-Anttila 1992). The methodology consists of predicting the pressure drop across the test element as a function of mass flow rate with constant power input. If a minimum in pressure drop occurs, then flow rates less than the minimum are unstable. The reason that a minimum can occur is due to the effect of increasing gas 
viscosity with temperature. Pressure drop is proportional to viscosity, (in the laminar flow regime), and the temperature is inversely proportional to the flow rate, thus, depending upon boundary conditions, a low flow rate could result in very high temperatures with corresponding high viscosities and pressure drops. The results of the one-dimensional analysis are shown in figures 2 and 3 for the High PHI test.

Figure 2. The Predicted Pressure Distribution across the FIT Element with a Flow Rate of 0.32 $\mathrm{Kg} / \mathrm{m}^{2} / \mathrm{s}$ and a Power Generation rate of 40 $\mathrm{W} / \mathrm{cm}^{3}$.

Shown in Figure 2 is the predicted pressure drop across the element at a mass flow rate of 0.32 $\mathrm{Kg} / \mathrm{m}^{2} / \mathrm{sec}$. A flow meter was present in the experiment, however the data indicated a discrepancy in the energy balance if it is assumed that the flow meter had an accurate reading. Since the gas used in the experiment was helium at an elevated pressure while the flow meter was calibrated for air at different conditions, it is quite reasonable to assume that the flow meter reading was not adequately corrected for

the actual gas conditions. Because both electrical power and temperature are quite easy to measure with a high degree of confidence, it was assumed that these readings could be used in establishing the actual flow rate in the experiment by a simple energy balance. Thus the flow rate of 0.32 was assumed to be the mean flow rate in the experiment based upon an energy balance that assumes the mixed mean thermocouple reading is accurate, and the power measurement is accurate.

The pressure distribution shown in Figure 2. indicates that the hot frit dominates the pressure drop for the entire element. This implies that the effect of the hot frit does have a major impact in determining the stability and flow maldistribution behavior of the element. Clearly a feedback mechanism is in effect here, the heat source is the electrically heated screen whereas the dominant pressure drop is the unheated hot frit. The total pressure drop for the element is therefore affected by the influence of heat transport between the heated screen and the hot frit. (The pressure drop dominance of the hot frit is not prototypic of current fuel element designs so that any conclusions regarding the stability of the FIT element cannot be directly extended to actual designs). 
Figure 3 is a curve of the pressure drop verses mass flow rate for the FIT element operating at the maximum power level attained in the experiment. As in previous analysis the minimum in the curve is the marginal stability point for the element. The flow rate used in the High PHI experiment is slightly less than the minimum which implies that the experiment should have had a flow instability at the higher power levels, and this is consistent with the data - hence a 1-D stability analysis is supported by experimental data.

Figure 3. The Pressure Drop Across the Fit Element as a Function of Flow Rate with a Constant Power Generation Rate of $40 \mathrm{~W} / \mathrm{cm}^{3}$.

\section{TWO-DIMENSIONAL ANALYSIS}

The two-dimensional analysis consists basically of a direct simulation of the experiment. Examining the experimental data reveals a large spread in the thermocouple readings for both the Low and High PHI tests. The spread in the temperature data comes from the many built in flow perturbations in the experiment. There were welded seams in the hot and cold frits of scale length 1 and $2 \mathrm{~mm}$ respectively. In addition there were Mollier patterns present that are created by overlapping screens. The Mollier patterns are of large wavelength when the overlapping screens are of the same mesh, because they are created by the holes of one screen overlying the wires in the adjacent screen. One only needs to hold two screens up to a light source to see these patterns.

Another source of flow variations is due to the manner in which the apparatus was constructed. The screen was tightly coiled about the hot frit, inserted into the cold frit, and then allowed to uncoil into a relaxed state. The effect of uncoiling causes small axial gaps to form which are distributed in an unknown fashion within the simulated fuel region. These axial gaps can allow the flow to redistribute axially with very little flow resistance. There are also other sources of perturbations such as power variation within the heated screen and a misaligned overlap at the beginning and end of the screen. 
The actual magnitude of many of the built in flow perturbations were not known to the experimenter nor could they be measured. Therefore, the magnitude of the flow perturbations must be estimated based upon ones own judgment. To this end the known perturbations, such as the welded seams, were modeled directly as blockages of known size. The unknown flow perturbations due to Mollier patterns were modeled as two equal size regions of different hydraulic diameter, 475 and 525 microns. The hydraulic diameters chosen straddle the actual 500 micron hydraulic diameter of the screen. The axial gaps that were present due to uncoiling of the screen were modeled as a single gap running the full axial length of the element between the cold frit and the heated screen. The width of this gap was $1 \mathrm{~mm}$.

The hydraulic diameter enters into the flow calculation in two ways. The heat transfer between the gas and the screen was modeled by a standard heat transfer correlation for flow through a porous bed (Edwards et. al. 1979) and this correlation aepends upon the hydraulic diameter. The Ergun equation for pressure drop through porous media (Bird et. at. 1960) was used to model the flow resistance and this correlation likewise depends upon the hydraulic diameter.

By performing a number of separate calculations the magnitude of the flow maldistributions were found to depend strongly upon the type of flow perturbation. The order of sensitivity of the flow maldistributions to the various sources of flow perturbations is:

1. The small axial gap between the cold frit and the screen;

2. The hydraulic diameters of the two fuel regions;

3. The welded seams.

Although the axial gap is not a true flow perturbation, since it runs the entire axial length of the element, it has the effect of greatly amplifying the effect of other perturbations.

Shown in Figure 4 is a plot of the F2D prediction for the hot frit temperature at a few selected locations and a comparison plot of the experimental data. Both curves are for the Low PHI test which had a large spread in the thermocouple data but did not show any indication of flow instability. A comparison shows reasonable agreement between the numerical simulation and the experimental data. There are two comparisons that are of importance. First is the time scale of growth of the temperature spread, and second is the absolute magnitude of the temperature spread.

Figure 5. shows the predictions and experimental data for the High PHI test. The only difference between these two tests is that the inlet $\mathrm{He}$ gas was at a much colder temperature ( $100 \mathrm{~K}$ versus $293 \mathrm{~K}$ ), the electric power was raised to a much higher level $(7 \mathrm{~kW}$ versus $1.8 \mathrm{~kW})$, and the flow rate was higher $(6 \mathrm{~g} / \mathrm{s}$ versus $1.8 \mathrm{~g} / \mathrm{s})$. Thermal instability in this test is inferred by the fact that some temperatures decreased as the 
Figure 4. A Comparison of the F2D Prediction and the Low Phi FIT Experiment. The F2d Prediction is on the Left and the Experimental Result is on the Right.

Figure 5. A Comparison of the F2D Prediction and the High Phi FIT Experiment. The F2d Prediction is on the Left and the Experimental Result is on the Right.

electric power increased. The F2D calculation used the same input file as the Low PHI test with reguard to the geometric, heat transfer and other parameters, and the 
appropriate flow and power parameters associated with this test. It is important to note that the predicted behavior is similar to the measured behavior though exact agreement could not be expected in light of the many uncertainties.

The agreement shown in figures 4 and 5 is the result of a few iterations of calculations and comparisons. To this end it should be pointed out that if no flow perturbations were introduced there would be no apparent signs of instability over the time scale of the experiment. Instead the instability would take a considerably larger amount of time to grow to a magnitude were rapid non-linear growth would occur. This points out the important effect that large perturbations have on the time scale of the growth of instabilities. A linear stability analysis would predict an instability to exist in the present case, but it would seriously underestimate the rate of growth. The reason is that the temperature perturbations were already in the non-linear-growth-rate regime when the power level was raised into the unstable zone.

\section{SUMMARY AND CONCLUSIONS}

The F2D code has been used to analyze the FIT experiments. The same methodology that is being used in other types of stability analyses was used in this experiment stability analysis. The one-dimensional analysis indicated that the hot frit dominated the pressure drop and therefore controlled the stability behavior of this experiment. A pressure drop vs flow rate curve of the experiment indicated that at the higher power levels the element should be instable, and this was corroborated by the experimental data. The two-dimensional simulation behaved in a manner that was very similar to the experimentally measured behavior. In conclusion the FIT experimental analysis yields partial code validation of F2D, and in addition it also validates the methodology that is used in analyzing thermal flow stability.

\section{Acknowledgments}

This work was performed at Sandia National Laboratories for the Department of Energy under Contract DE-AC04-76DP00789. The author wishes to thank George Maise and Timothy Lawrence at Brookhaven National Laboratories for their help in providing the experimental data, descriptions of the experimental apparatus, and procedures.

\section{$\underline{\text { References }}$}

Bird R.B., W.E. Stewart, E.N. Lightfoot. Transport Phenomena. John Wiley and Sons. N.Y. 1960.

Black D. L. (1993) "Laminar Flow Instability in Nuclear Rockets" in Proc. 10th Symposium on Space Nuclear Power and Propulsion. CONF-930103, MS El-Genk and Mark D. Hoover, American Institute of Physics, New York Albuquerque N.M. 
Edwards D.K., V.E. Denny, A.F. Mills. Transfer Processes. 2nd Edition McGraw Hill Book Company. 1979.

Suo-Anttila A.(1993) "F2D: A Two-Dimensional Compressible Gas Flow Code," in Proc. 10th Symposium on Space Nuclear Power and Propulsion. CONF-930103, MS El-Genk and Mark D. Hoover, American Institute of Physics, New York Albuquerque N.M. 1993.

Witter J. K., D.D. Lanning, J.E. Meyer. (1993) Flow Stability Analysis of a Particle Bed Reactor in Proc. 10th Symposium on Space Nuclear Power and Propulsion. CONF930103, MS El-Genk and Mark D. Hoover, American Institute of Physics, New York Albuquerque N.M.

\section{DISCLAIMER} This report was prepared as an account of work sponsored by an agency of the United States Government. Neither the United States Gnvernment nor any agency thereof, nor any of their employees, makes any warranty, express or implied, or assumes any legal habaratus, product, or bility for the accuracy, completeness, or usefulness of any information, appand rights. Referprocess disclosed, or represents that its use would not infringe private by trade name, trademark, ence herein to any specific commercial product, process, or service by its endorsement, recommanufacturer, or otherwise does not necessarily constitute or imply agency thereof. The views mendation, or favoring by the United States Governmentarily state or reflect those of the and opinions of authors expressed herein do not

United States Government or any agency thereof. 


\section{Fit Element Model}

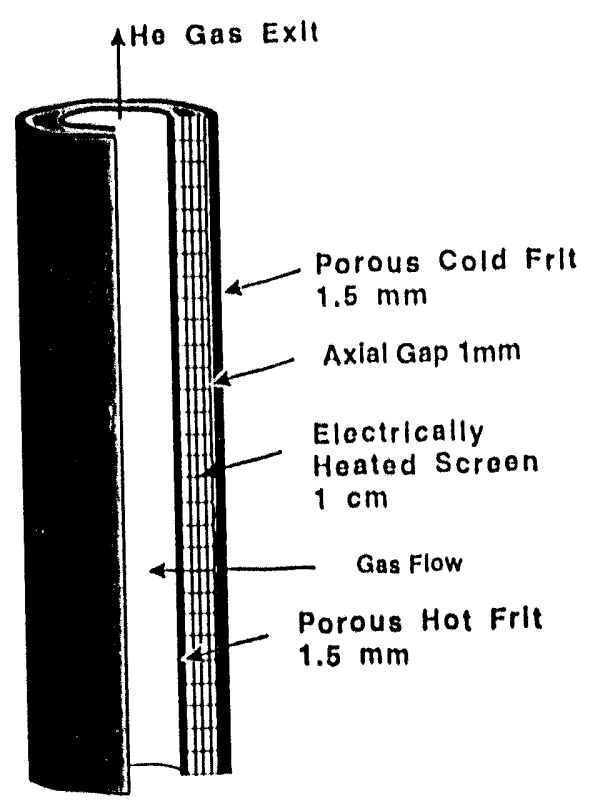

Figure 1. A Schematic Diagram of the FIT Element

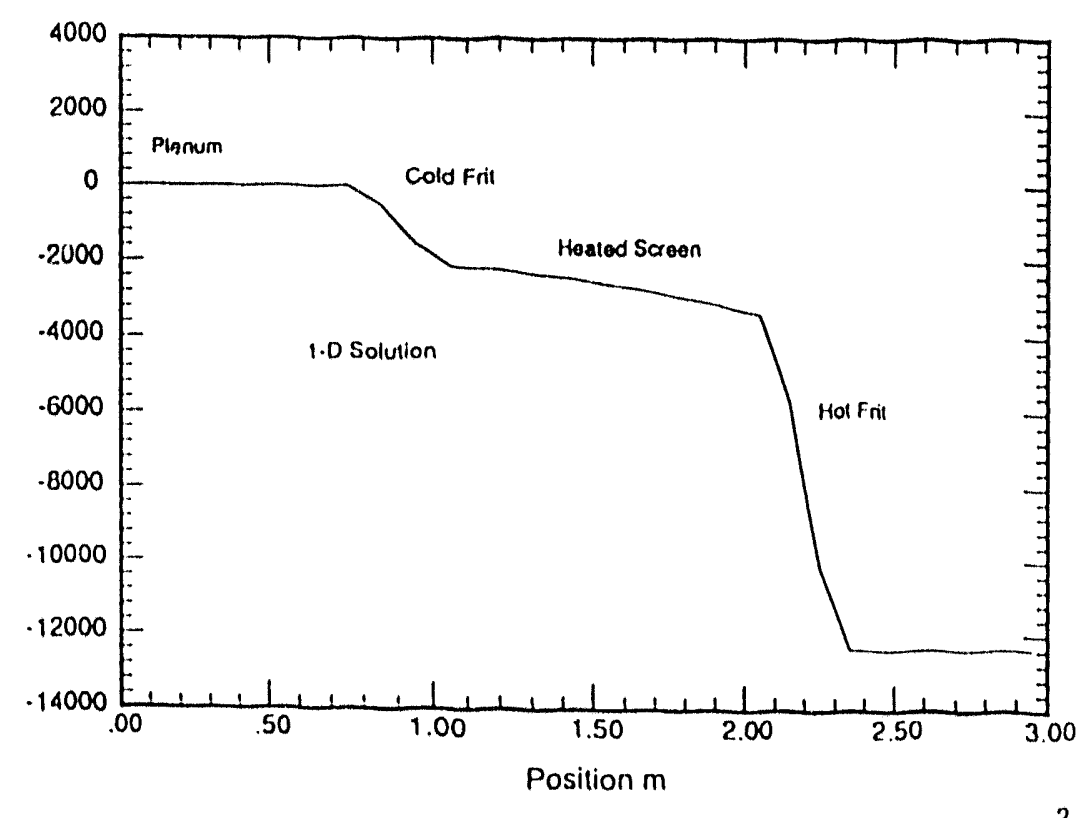

$.10^{-2}$

Figure 2. The Predicted Pressure Distribution Across the FIT Element With a Flow Rate of $0.32 \mathrm{~kg} / \mathrm{m}^{2} / \mathrm{sec}$ and a Power Generation Rate of $40 \mathrm{~W} / \mathrm{cm}^{3}$. 


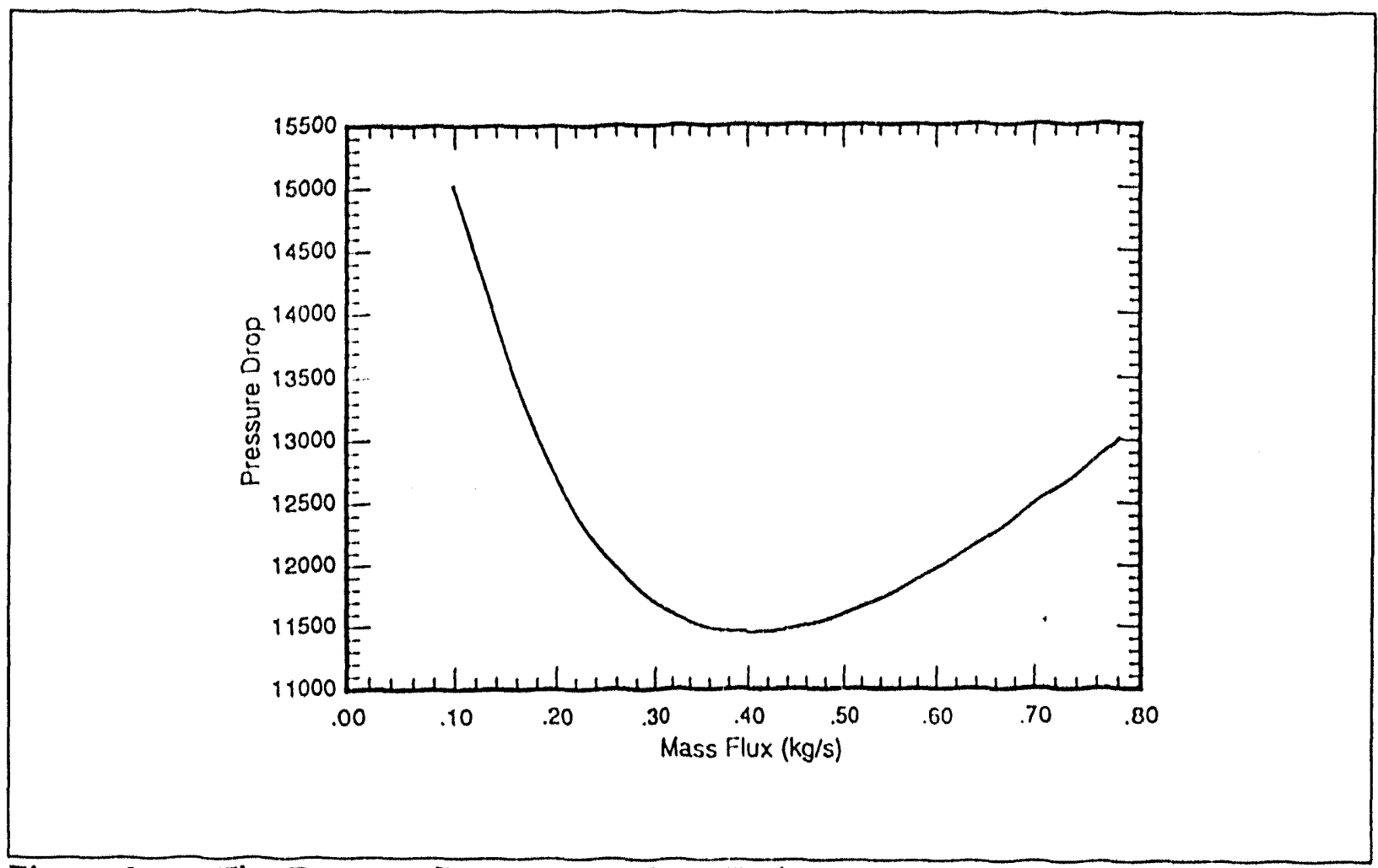

Figure 3. The Pressure Drop across the FIT Element as a Function of Flow Rate with a Constant Power Generation Rate of $40 \mathrm{~W} / \mathrm{cm}^{3}$.

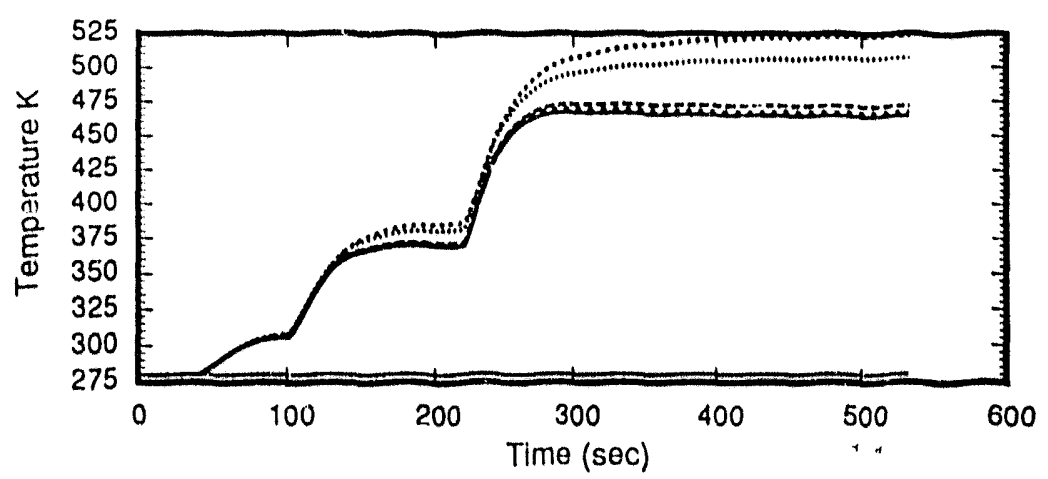

Figure 4. The F2D Prediction for the Hot Frit Tempe.ature at Several Different Locations for the LOW PHI Test. 


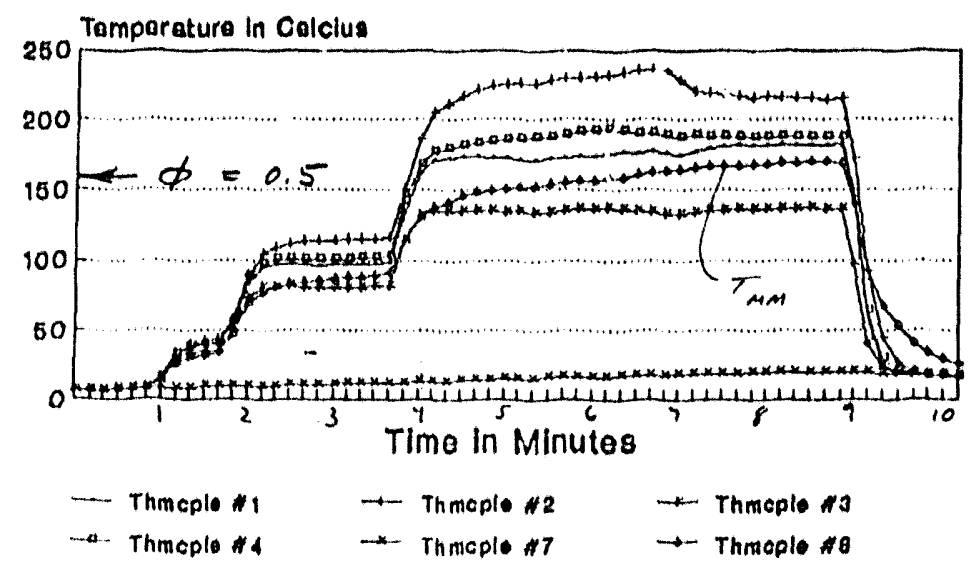

Preliminary Figuve, Final not yet a vailable

Figure 5. The Experimental Data for the Hot Frit Temperature at Several Different Locations in the LOW PHI Test.

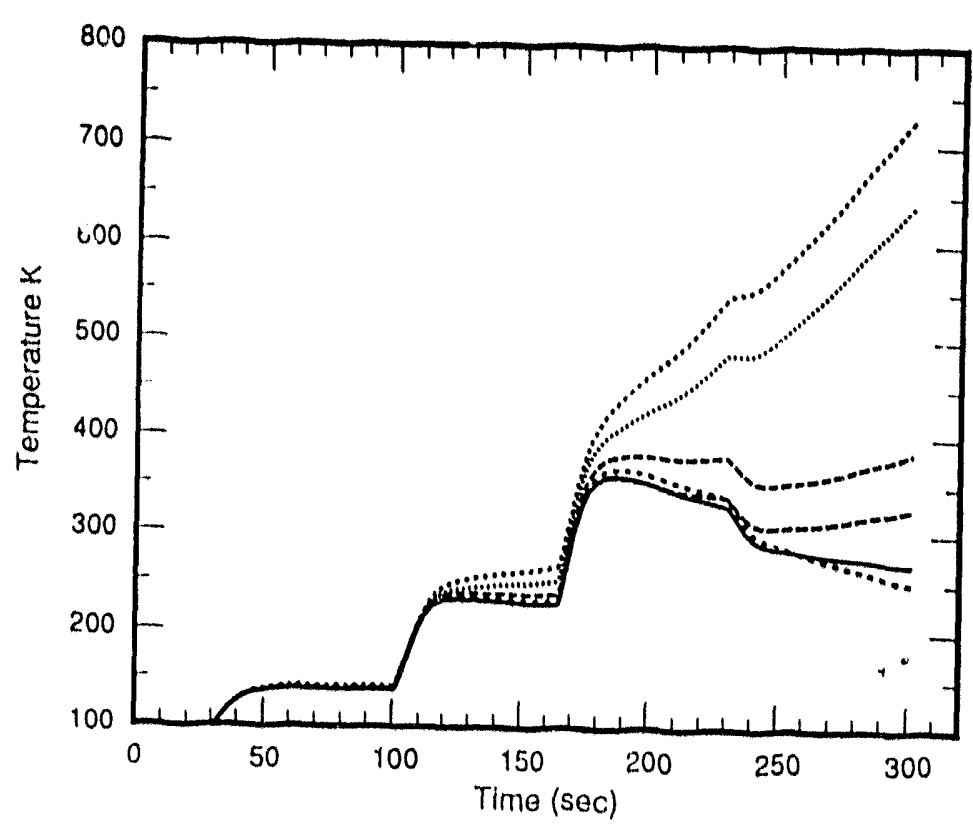

Figure 6. The F2D Prediction for the Hot Frit Temperature at Several Different Locations for the HIGH PHI Test. 


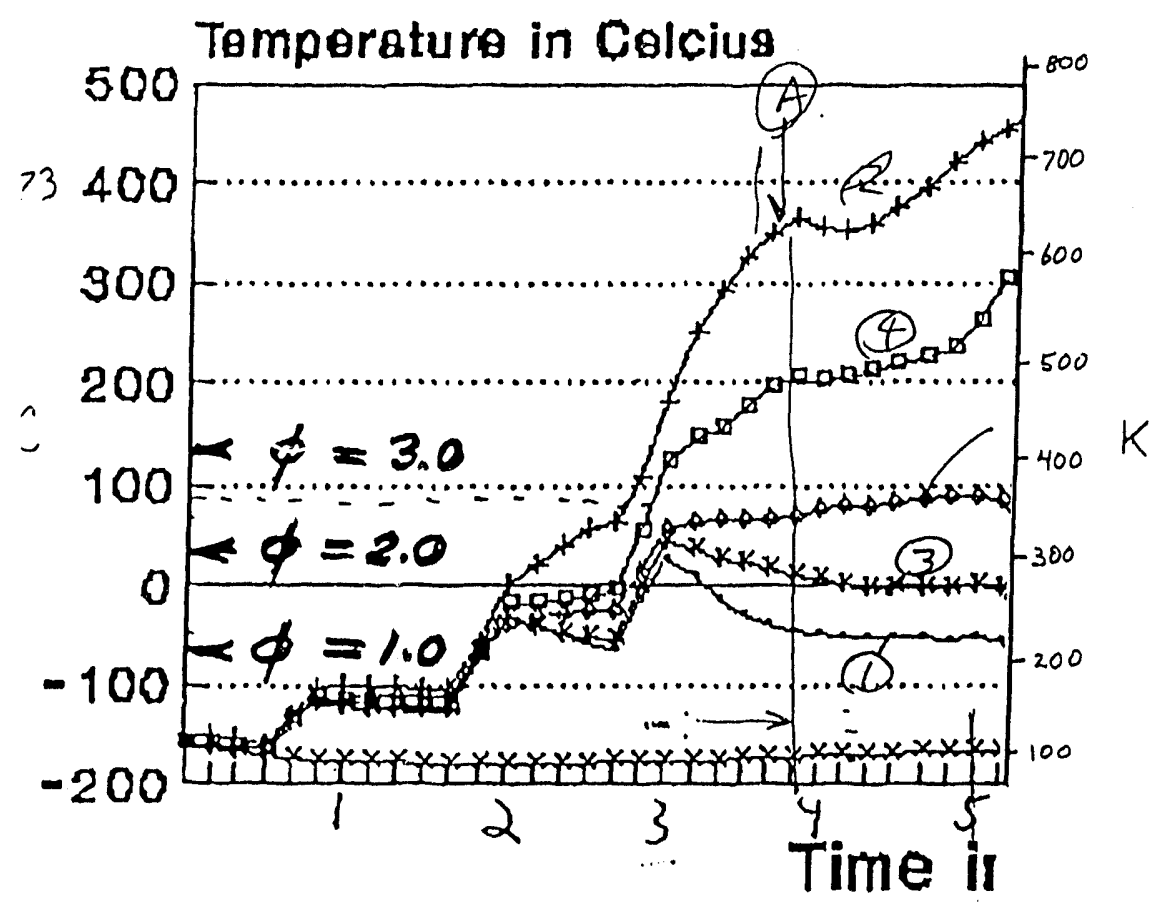

Figure 7. The Experimental Data for the Hot Frit Temperature at Several Different Locations in the HI PHI Test.

Preliminary figure

Final not get puaildale 

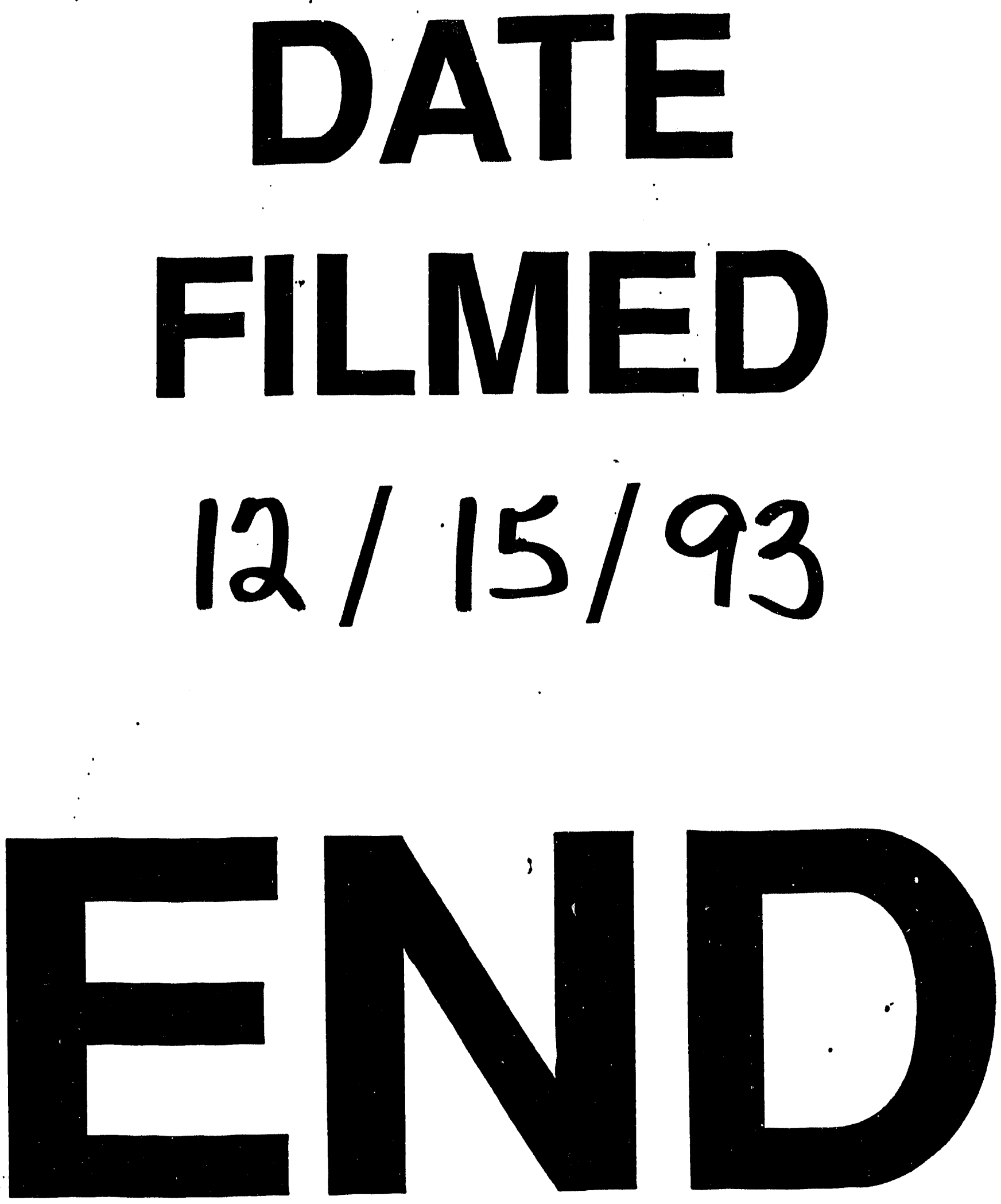
<smiles>C=CC</smiles>

$\longrightarrow$ 